\title{
Testing Alternative Techniques of Numerical Simulation versus Repeated Field Instrumental Measurements for Assessing Soil Salinity Status in a Sodic Grassland
}

\author{
T. TÓTH and L. KUTI \\ Research Institute for Soil Science and Agricultural Chemistry (RISSAC) \\ of the Hungarian Academy of Sciences, Budapest and \\ Hungarian Geological Institute, Budapest
}

\section{Introduction}

Soil salinization is a process that threatens the success of sustainable agricultural production. On the other hand, salinization is a natural process in many habitats and therefore it is also an important phenomenon for maintaining the biodiversity of native ecosystems. Soil salinization is guided by the pattern of water movement in soils and the subsoil and is therefore not a one-, but rather a three-dimensional process (SEELIG \& RICHARDSON, 1994). As elements of the hydrological cycle exhibit strong temporal variation, soil salinization is characterized by spatio-temporal variability.

In the Great Hungarian Plain the salinity and sodicity status of soils is closely related to the topography and hydrogeological conditions (VÁRALLYAY, 1999; ТÓTH et al., 2001). In order to describe the effect of expected extreme weather situtations and changes in the ecological status of habitats, it is necessary to compile maps of soil salinity of both native and cropped salt-affected areas. Compared to the traditional mapping of salt-affected soils with instrumental field methods (RHOADES \& MIYAMOTO, 1990) it seems practical to use simulation programs to predict the salinity status of soils. An evident question arises: is it worthwhile to use numerical simulation programs for predicting the soil salinity status of individual sites, or a full plot?

The objective of present study was to compare the performance of two alternative techniques for the temporal assessment of soil salinity in a sodic grassland: a) using numerical simulation model, and b) systematic monitoring carried out with field salinity probe.

Correspondence to: Dr. Tibor TÓTH, Research Institute for Soil Science and Agricultural Chemistry (RISSAC) of the Hungarian Academy of Sciences, H-1022 Budapest, Herman Ottó út 15. Hungary. E-mail: tibor@rissac.hu 


\section{Materials and Methods}

Study site

A $300 \times 600 \mathrm{~m}$ natural pasture area of meadow solonetz soils (Hungarian soil classification), in the Hortobágy region of Hungary was selected. This field site was described in detail by OERTLI and RAJKAI (1988), TÓTH and JOZEFACIUK (2002).

\section{Catena of soils and plant associations}

In the native sodic (,solonetzic") salt-affected landscapes of the Great Hungarian Plain the distribution of plant species and the zonation of the plant associations follow the pattern of the elevation, as it was described earlier by BODROGKÖZY (1965), and within the study site by TÓTH et al. (1991) as well as TÓTH and RAJKAI (1994).

It is a widespread concept to use elevational zonation to delineate types of soils on variable undulating terrains (PARK et al., 2001). On lowlands this approach does not provide a sufficient strength of correlation because of the slight variation in elevation. According to world-wide experience, salt-affected lands are good exceptions, in which - due to the strong abiotic effect of salt accumulation - the clear and sharp depth distribution of salts and the presence of saline groundwater result in a very clear elevational zonation of vegetation and soils (ALVAREZ et al., 2001).

\section{Classification of the site into separate strata of salt accumulation status}

The procedure of classifying the observation points was K-means clustering. According to the conceptual model, it was assumed that three zones of salt accumulation status (ТóTH et al., 2001) exist. The variables used for K-means clustering were the following for each measurement point: elevation, vegetation category, average laboratory $\mathrm{EC}_{2.5}$, average field measured bulk soil electrical conductivity, $\mathrm{EC}_{\mathrm{a}}$ for the $0-20$ and $0-40 \mathrm{~cm}$ depths. The average was calculated from 15 repeated observations.

\section{Field observations and analysis}

The following scheme compares the work requirement of the alternative techniques for our study site. Repeated steps are indicated with underlined characters, steps involving probabilistic approximations, such as statistical inference and classification are marked with italic characters. Mechanistic simulation is indicated with bold characters. 


\section{STANDARD MAPPING THROUGH REPEATED INSTRUMENTAL OBSERVATIONS \\ - measurements at 420 points every 4 months \\ - parallel sampling and laboratory analysis at 20 points \\ - calculation of calibration regression equation between field $E C_{a}$ and lab $E C_{2.5}$ \\ - prediction of the $E C_{2.5}$ of the 420 points \\ - interpolation for creating a contour map of $\mathrm{EC}_{2.5}$ values}

\section{ALTERNATIVE MAPPING THROUGH NUMERICAL SIMULATION \\ - previous data collection \\ - classification of the site into 3 strata based on the factors of salt accumulation \\ - selection of 3 soil profile sites \\ - sampling of 3 soil profiles, analysis of samples \\ - collection of regular meteorological and groundwater input data \\ - simulation of salinization for the 3 soil profiles \\ - spatial extrapolation of the simulated EC values for 3 strata \\ - interpolation for creating a contour map of EC values}

Considering a situation when the basic data on classifying the sampling points are available, mapping through repeated instrumental observations requires about 50 times more active working time than simulation modelling.

\section{Repeated mapping}

The soil bulk electrical conductivity $\left(\mathrm{EC}_{\mathrm{a}}\right)$ was measured with a 4-month frequency at 420 points, arranged systematically in a $25 \times 25 \mathrm{~m}$ grid. The equipment used for the measurements was a four-electrode probe (RHOADES \& МіYАмОто, 1990). At 20 points soil samples were collected from $10 \mathrm{~cm}$ increments to the depth of $40 \mathrm{~cm}$. Duplicate sample collection was made between the endpoints of the probe, but the samples were bulked for each depth increment. In the laboratory $\mathrm{EC}_{2.5}$ was determined in 1:2.5 soil:water suspension.

\section{Characterization of the selected profiles and repeated sampling for testing numerical simulations}

At the 3 selected profiles first a morphologic description and horizon-wise sampling for laboratory analysis was carried out. This was followed by a series of 15 repeated samplings, performed by sampling the soil down to the groundwater. The level and composition of the groundwater were also characterized. In the present paper data of those 4 mapping dates are given which fell into the period of sampling for numerical simulation: 15 September, $1998\left(50^{\text {th }}\right.$ day of data collection, marked as 98IX15; 28 April, 1999 (275 ${ }^{\text {th }}$ day $)$, marked 99IV28; 
15 July, 1999 (353 ${ }^{\text {rd }}$ day), marked 99VII15; 20 September, 1999 (420 $0^{\text {th }}$ day) marked 99IX20.

Soil was analyzed in the laboratory according to the methods described in BUZÁs (1988). Saturated hydraulic conductivity $\left(\mathrm{K}_{\mathrm{s}}\right)$ was measured on $5 \mathrm{x} 5 \mathrm{~cm}$ undisturbed cores with the „falling head" technique. Soil moisture was determined by the gravimetric method.

\section{Statistical analysis}

The field $\mathrm{EC}_{\mathrm{a}}$ measurement points were classified with $\mathrm{K}$-means clustering, which identifies homogeneous clusters of the measurement points, based on selected soil and vegetation characteristics. The distances between the clusters were calculated with simple Euclidean distance. Based on the conceptual model, the number of clusters was specified to be 3 .

The spatial correlation of measured and predicted EC values of the points was evaluated on the basis of semivariograms (WEBSTER, 1980).

\section{Numerical simulation}

Two process-based mechanistic simulation models were used, LEACHM (WAGENET \& HUTSON, 1987) and UNSATCHEM (SIMUNEK \& SUAREZ, 1993). The data collection was designed specifically in view of the input data requirement of the two numerical simulation models.

\section{Spatial extrapolation}

The EC values predicted by numerical simulation for the days of field survey of $\mathrm{EC}_{\mathrm{a}}$ were taken as values for the three individual strata of the 420 points. For the visual interpretation, that is the preparation of the two sets of maps, the data were interpolated with the same technique: inverse distance square.

\section{Results and Discussion}

\section{Classification of $420 E C_{a}$ observation points into three different strata}

As a result of K-means clustering of the 420 points, 3 final cluster centers were calculated. Cluster group No. 1, the zone of "Waterlogging" corresponds to the deepest lying wet "meadow" places with Alopecuretum pratensis (plant association) for which the characteristic profile selected was No.419=ME, where the soil type is Haplic Solonetz (FAO-UNESCO). Cluster group No. 2, the zone of "Accumulation" is the intermediate elevational group of the most sodic Artemisio-Festucetum pseudovinae grasslands in which profile 
No.249=SH is a Salic Solonetz (FAO-UNESCO). Cluster group No. 3 is the zone of "Leaching", the least sodic Achilleo-Festucetum pseudovinae grassland with the selected profile No.6=GR, a Mollic Solonetz (FAO-UNESCO). The groups were quite distinct on the area map (Figure 1) and were used to predict salt accumulation by means of numerical simulation.

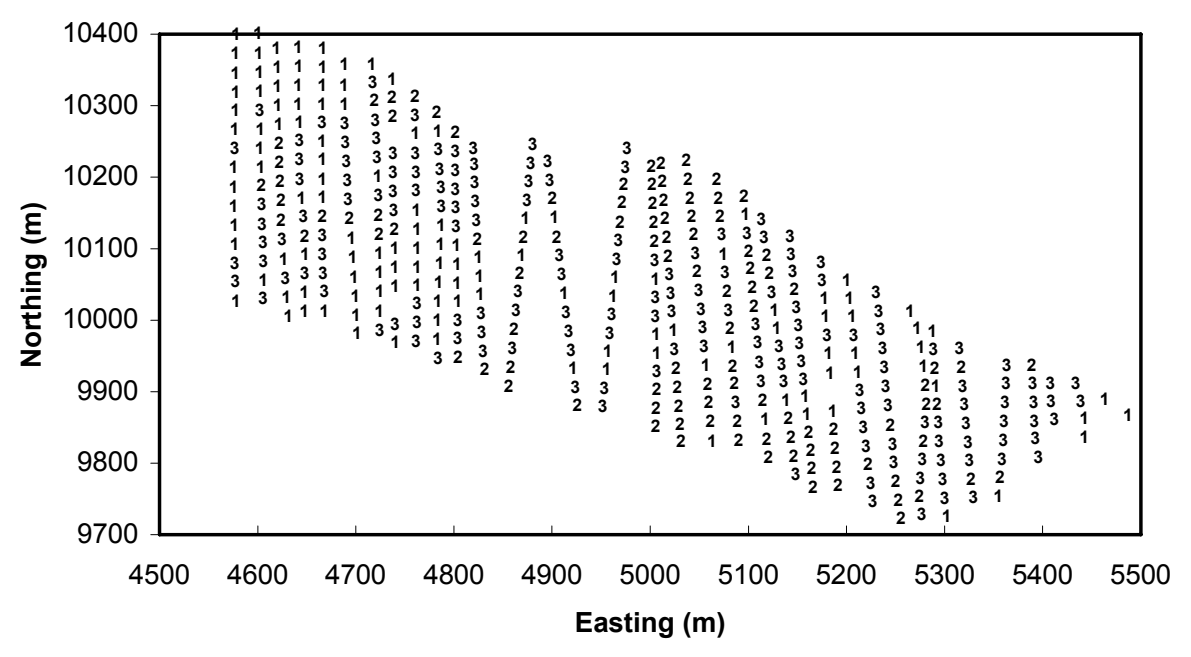

Figure 1

Cluster membership of $\mathrm{EC}_{\mathrm{a}}$ measurement locations derived by $\mathrm{K}$-means clustering algorithm

\section{Characteristics of the selected soil profiles}

As the position of the profiles on the toposequence is closely related to the vegetation (TóTH \& RAJKAI, 1994) and the soil properties, the kind of vegetation is used to abbreviate the names of profiles: GR (tallgrass within the zone "Leaching") with deep meadow solonetz (national classification), SH (shortgrass within the zone "Accumulation") with medium meadow solonetz, and ME (meadow within the zone "Waterlogging") with medium meadow solonetz soils. Approximate equivalent terms of US Taxonomy are: GR: Natrustoll, SH: Natrustalf, and ME: Natraquoll.

The profiles showed significant differences in chemical properties such as $\mathrm{EC}, \mathrm{SAR}$ and $\mathrm{pH}$. The $\mathrm{SH}$ profile, located on an intermediate elevational position is the most sodic and saline of the three.

\section{Results of numerical simulation}

In this discussion only results from the $0-40 \mathrm{~cm}$ surface layer are discussed, as only this depth has been characterized by the independent instrumental field $\mathrm{EC}_{\mathrm{a}}$ measurements. 
The numerical simulation of soil salt accumulation is based on the adequate description of the soil's moisture regime. Basically the results of numerical simulation showed the pattern of the dynamics of measured moisture content. The average differences between the profiles are evident. It was also noticeable that during the study period the moisture content of the SH profile was greater than that of the ME profile during some periods. The two numerical simulation programs described the soil moisture dynamism very similarly.

Figure 2 shows the measured and simulated electrical conductivity of the $0-40 \mathrm{~cm}$ soil layer. The direct comparison of the figure is difficult, because the simulation programs provide the instantaneous EC of the soil solution. It is not practical to collect this soil solution at most moisture contents in the studied clay loam soil. For comparing the salinity status of the measuring sites the easily measurable EC of 1:2.5 soil:water suspension was applied.

As it can be seen in Figure 2, the measured EC varied greatly. On the one hand this variation is partly due to the used augering technique, because it does not permit the sampling of the same "point" again. The variation in EC is due to the large lateral and depth variation of the soils. The temporal change of EC values in the three profiles was characterized similarly by the two simulation programs (Figure 2), that is the difference between the points and the temporal pattern was the same. It shows that although the EC of the most sodic "SHshortgrass" profile is generally the largest, during some periods the salinity of the $0-40 \mathrm{~cm}$ layer may increase in such a way that profile "ME-meadow" can have larger values.
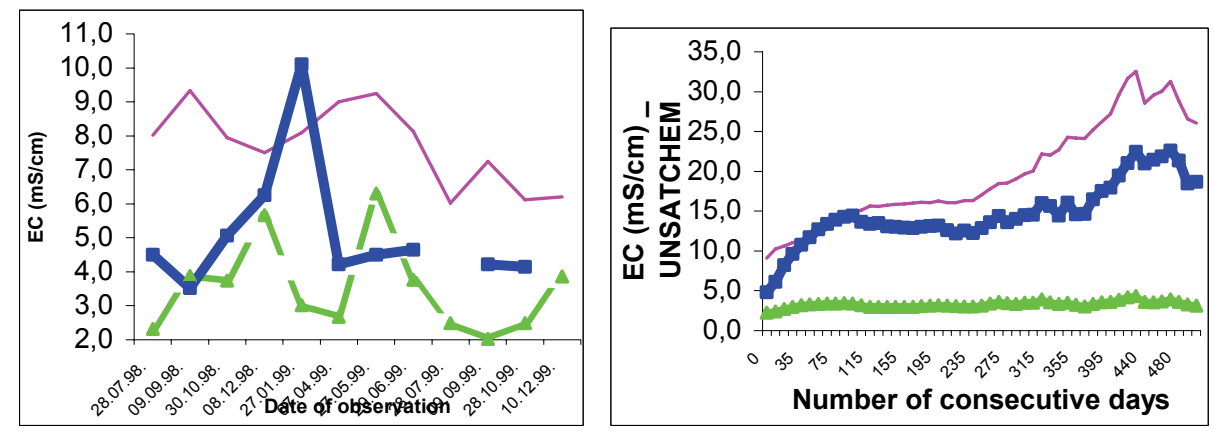

Figure 2

The measured (EC2.5 on the left side) and predicted (right side with UNSATCHEM simulation program) average soil EC of the $0-40 \mathrm{~cm}$ layer in the three selected soil profiles of the three distinguished classes of salt accumulation status.

Thick grey triangles indicate GR-tallgrass, smooth fine lines SH-shortgrass, and thick black squares ME-meadow profiles 


\section{Comparison of the maps obtained with the two techniques}

The broad pattern of EC provided by the maps were very similar, since all were based on the same spatial pattern. In the case of measured data (Figure 3) it was provided by the existing differences between the points, and in the case of the numerically simulated values it was provided by the original database of average EC values.
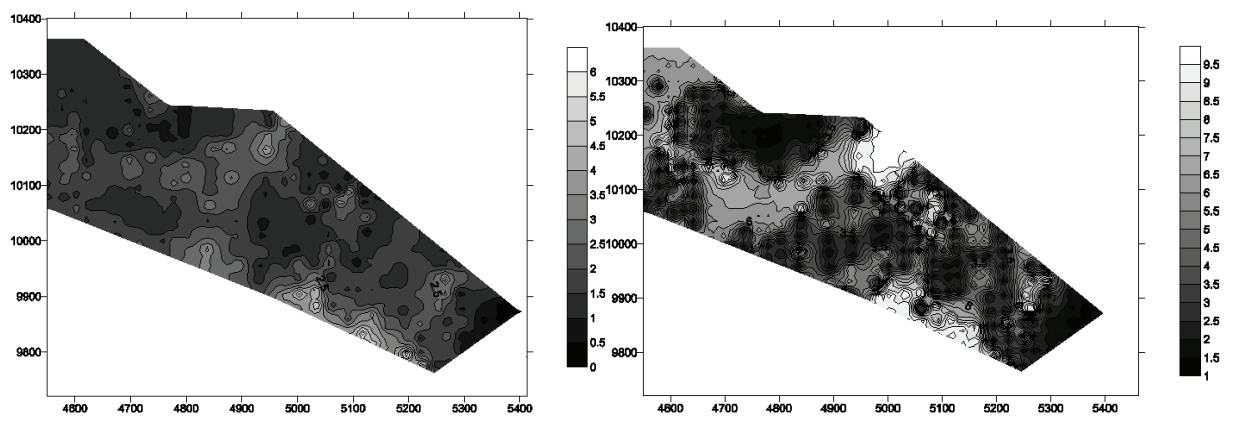

Figure 3

Map of "measured" EC $\mathrm{E}_{2.5}$ of 20 September ,1999 (left side) and EC of actual soil solutions based on simulations for 20 September, 1999 performed on 3 profiles with UNSATCHEM.

The distances on $\mathrm{X}$ (easting) and $\mathrm{Y}$ (northing) axes are indicated in meters. The legend shows the $\mathrm{EC}$ in $\mathrm{mS} / \mathrm{cm}$

Nevertheless, the small number of numerically simulated profiles, or the small number of strata distinguished, provided a very uneven lateral variation of EC on the maps - as the exemplary map of 20 September, 1999, made on the basis of simulations with UNSATCHEM (Figure 3) - shows. Here the simulated $\mathrm{EC}$ for the strata of ME, SH and GR profiles was $6.6,9.9$ and $1.3 \mathrm{mS} / \mathrm{cm}$, respectively.

Although it is evident (Figure 1) that there are several depressional points with the characteristic meadow vegetation that correspond to the No. 1. cluster, these usually show a smooth lateral variation. However, on the map obtained with the numerically simulated values the inverse distance square algorithm did not smooth out the variation acceptably.

\section{Comparison of the semivariograms of EC values}

The semivariogram was calculated to compare the spatial correlation of the $\mathrm{EC}$ values obtained with different techniques, that is measurement and calibration, and simulation and extension.

Differences were found in the semivariograms calculated for the measured and simulated data of the 20 September, 1999 example (Figure 4). 

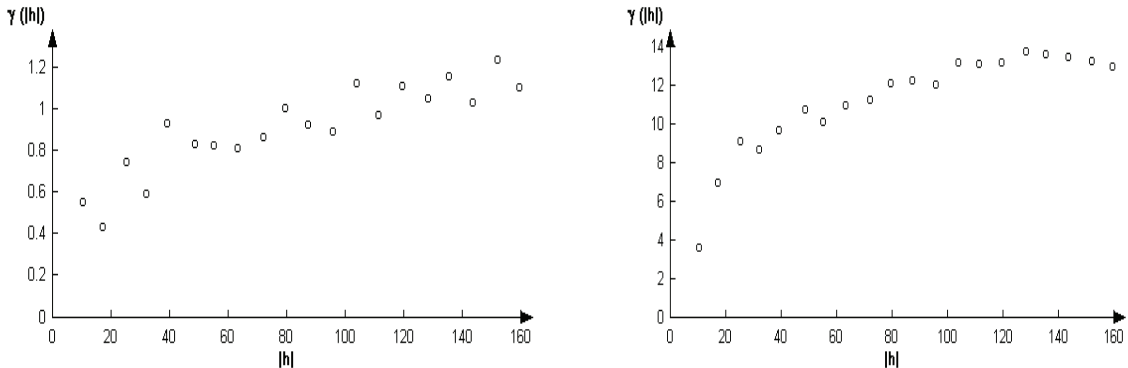

Figure 4

Semivariances of "measured" $\mathrm{EC}_{2.5}$ based on $\mathrm{EC}_{\mathrm{a}}$ measurements made at 420 points and 20 calibration samples on 20 September, 1999 (on left side) and EC of soil solution based on simulations for three profiles and substituted for the three strata distinguished (on right side). On the $\mathrm{X}$ axis distance is shown in meters, on the $\mathrm{Y}$ axis the semivariance is shown in $(\mathrm{mS} / \mathrm{cm})^{2}$

The range of spatial dependence is the same for the two semivariograms, but great short-range variation of $\mathrm{EC}_{2.5}$ and larger nugget variance occurs. On the one hand the semivariogram of EC simulated with UNSATCHEM shows smooth variation at short distances and small nugget variance. This is the result of the previous classification of the 420 points, because with the use of clustering the class of the points, therefore the spatial pattern, has been decided for each simulated and mapped date. In this classification the average $\mathrm{EC}_{2.5}$ values were very important. On the other hand, the measured values carry the effect of "noise" of the momentary weather, groundwater etc conditions. The differences in the sill values of the semivariograms are the result of the difficulties of collecting "real" soil solution (as described above).

\section{Relationship between the measured and predicted maps}

For the measurement points the correlation between measured and predicted EC values was calculated, again only the results of 20 September, 1999 and of the UNSATCHEM simulations are discussed. The Pearson correlation coefficient was significant at the 0.01 level between the "measured" $\mathrm{EC}_{2.5}$ and predicted EC (0.49), but its value was larger for the average (15 times measured) $\mathrm{EC}_{2.5},(0.78)$.

\section{Conclusions}

The maps of salinity obtained by numerical simulation and spatial extrapolation showed close correlation with the measured data. Comparing the difference in cost between the two techniques, the maps received with simulation are inexpensive. 
The spatial structure of the salinity in the studied grassland is very stable, the $\mathrm{EC}_{2.5}$ values determined on consecutive sampling dates are very closely related, as shown by the correlation coefficients. The average $\mathrm{EC}_{2.5}$ of the measuring sites expresses this structure well.

There are two suggested ways to improve the prediction: by the utilization of more strata for the extrapolation of the numerically simulated salinity values, and/or by more precise simulation of the salinity status of the grassland by the incorporation of subroutines describing characteristic features of continental sodic grasslands. Both ways are under development.

\section{Summary}

Within a $300 \times 600 \mathrm{~m}$ complex heterogeneous sodic grassland two techniques were compared for assessing soil salinity. The standard technique is based on repeated field instrumental measurements at 420 points. The alternative technique was performed with the use of numerical simulation of salt accumulation carried out on 3 profiles. These profiles have been selected as representatives of the distinct classes, or map strata of salt accumulation, distinguished with preliminary statistical clustering of the instrumental measuring points. Simulated values were extrapolated for the 3 strata distinguished. The maps obtained with the two techniques were statistically correlated. The use of numerical simulation is cost-effective. Further improvements are expected from a combination of improved numerical simulation and utilization of more strata.

Research and publication was supported by the EU Program No. PL970598, (Contract No. ENV4-CT97-0681) and the Hungarian Scientific Research Fund (OTKA) (Project Nos. T 023271, T025623, T 030738, T 037731).

Key words: sodic soil, salinization, conceptual model, numerical simulation

\section{References}

Alvarez Rogel et al., 2001. Edaphic characterization and soil ionic composition influencing plant zonation in a semiarid Mediterranean salt marsh. Geoderma. 99. 81-98.

BODROGKÖZY, GY., 1965. Ecology of the halophilic vegetation of the Pannonicum. II. Correlation between alkali ("szik") plant communities and genetic soil classification in the Northern Hortobágy. Acta Botanica Hungarica. 11. 1-51.

BuZÁs, I. (Ed.) 1988. Methods of Soil Analysis. (In Hungarian) Mezőgazdasági Kiadó. Budapest. 
OeRTLI, J. J. \& RAJKAI, K., 1988. Spatial variability of soil properties and the plant coverage on alkali soils of the Hungarian Puszta. In: Proc. Intern. Symp. Solonetz Soils, Problems, Properties and Utilization. Osijek, June 15-21, 1988. 156-161.

PARK, S. J., MCSWEENEY, K. \& LOWERY, B., 2001. Identification of the spatial distribution of soils using a process-based terrain characterization. Geoderma. 103. 249-272.

RhoAdes, J. D. \& Miyamoto, S., 1990. Testing soils for salinity and sodicity. In: Soil Testing and Plant Analysis. 299-336. SSSA Book Series. No. 3. Madison. WI.

SEelig, B. D. \&. Richardson, J. C., 1994. Sodic soil toposequence related to focused water flow. Soil Sci. Soc. Am. J. 58. 156-163.

SimuneK, J. \& SuAREZ, D. L., 1993. UNSATCHEM-2D Code for Simulating Twodimensional Variably Saturated Water Flow, Heat Transport, Carbon Dioxide Production and Transport, and Multicomponent Solute Transport with Major Ion Equilibrium and Kinetic Chemistry, Version 1.1. Research Report No. 128. U. S. Salinity Laboratory, USDA, ARS, Riverside, California.

TóTH, T \& JozefaciUK, G., 2002. Physicochemical properties of a solonetzic toposequence. Geoderma. 106. 137-159.

TÓTH, T. \& RAJKAI, K., 1994. Soil and plant correlations in a solonetzic grassland. Soil Sci. 157. 253-262.

То́тн, T. et al., 1991. Characterization of semi-vegetated salt-affected soils by means of field remote sensing. Remote Sensing of Environment. 37. 167-180.

TóTH, T. et al., 2001a. Use of digitalized hydrogeological maps for evaluation of saltaffected soils of large areas. Arid Land Research and Management. 15. 329-346

Tóth, T. et al., 2001b. Changes in the factors of salt accumulation in the study site "Nyírőlapos" of Hortobágy region. (In Hungarian) Agrokémia és Talajtan. 50. 409-426.

VÁrallyay, Gy., 1999. Processes of salinization and sodification in the Carpathian Basin. (In Hungarian) Agrokémia és Talajtan. 48. 399-418.

WAGENET, R. J. \& HUTSON, J. L., 1987. LEACHM-Leaching Estimation and Chemistry Model. Continuum 2. Water Resources Institute, Cornell Univ. Ithaca.

WEBSTER, R., 1980. Optimal interpolation and isarithmic mapping of soil properties. I. The semivariogram and punctual kriging. J. Soil Sci. 31. 315-331. 